DOI: 10.22616/REEP.2021.14.036

\title{
Development of Teachers' Digital Competence: Problems and Solutions in Latvia
}

(D)Svetlana Usca ${ }^{1}$ Dr. paed.; Janis Dzerviniks ${ }^{2}$ Dr. paed.; (DVelta Lubkina ${ }^{3}$ Dr. paed.

\author{
Aija Vindece ${ }^{4}$ Mg. paed.; Janis Poplavskis ${ }^{5}$ Dr. paed. \\ Rezekne Academy of Technologies, Latvia \\ svetlana.usca@rta.lv; janis.dzerviniks@rta.lv²; velta.lubkina@rta.lv³; \\ aijav2@inbox.lv $v^{4}$ janis.poplavskis@rv1g.lv ${ }^{5}$
}

\begin{abstract}
The data obtained from the Latvian National research programme "Life with COVID-19: Evaluation of the coming coronavirus crisis in Latvia and recommendations for social resilience in the future (CoLife)" show that the successful implementation of remote learning requires the improvement of teachers' digital competence. The professional development courses organized before the COVID-19 pandemic (their content, form) do not meet the needs of the real situation. It is necessary to look for new forms so that the content of professional development courses meets the needs of current general education teachers, including not only general skills characterizing digital competence, but also specific ones related to the level of education (age of learners) and field of study. The aim of the research: to identify the needs of general education teachers for the development of digital competence and to prepare proposals for the implementers of professional competence development courses. Research methods: online survey of 559 teachers, survey of 6 experts, quantitative data processing in SPSS program, content analysis of qualitative data. The research concluded that teachers' professional competence development courses should be practice-oriented, as close as possible to the technical capabilities of an educational institution, as well as considering the current needs of teachers, the field of subjects taught and the level of education at which they work.
\end{abstract}

Keywords: digital competence, Pedagogical Digital Competence, teachers' needs, professional development.

\section{Introduction}

In 2020, a technological revolution occurred in Latvia's education: if the positive and negative impact of technology on pupils' development was discussed previously, then due to the Covid-19 pandemic, all educational institutions switched to remote learning (RL) within a week. In Latvia, as in other countries, such a rapid transformation is associated with various obstacles and challenges. It is not just the Internet speed and availability of technology. The readiness of a teacher to implement the remote learning process is important. Research (Crawford et al., 2020) on higher education state that many teachers initially focused on content transfer online rather than online pedagogy. The same happened in general education. Teachers at all levels of education need to use information and communication technologies to implement meaningful self-directed learning. Digital competence became an integral part of general education's teaching and learning processes, and the professional development of teachers, which is considered "structured professional learning that results in changes to teacher knowledge and practice, and improvements in student learning outcomes" (Darling-Hammond, Hyler, Gardner, 2017, 2), became more relevant than ever. At all levels (individual, educational institutions, local governments and state), the main emphasis was placed on the improvement of teachers' digital competence, meaning technical skills in the use of various learning platforms and digital tools. However, this is not enough. Teachers' digital competence must be seen from a didactic pedagogical perspective in the context of education. The use of diverse ICT-based learning strategies for curriculum development and learning requires new knowledge from teachers about technologies, methods and learning processes (Cabero-Almenara et al., 2020). Issues on Technological Pedagogical Content Knowledge (TPACK model) become relevant, when technological knowledge, pedagogical knowledge and content knowledge are synergized (Mishra, Koehler, 2006; Hew et al., 2019). The term "Pedagogical Digital Competence" is also used in the literature, which is defined as "the ability to consistently apply the attitudes, knowledge and skills required to plan and conduct, and to evaluate and revise on an ongoing basis, ICT-supported teaching, based on theory, current research and proven experience with a view to supporting students' learning in the best possible way" (From, 2017, 48).We see that digital competence is only one, but an extremely important element of pedagogical digital competence, and qualitative implementation of RL is not possible without the improvement of this competence. 
The aim of the research: to identify the needs of general education teachers for the development of digital competence and to prepare proposals for the implementers of professional competence development courses.

\section{Methodology}

A questionnaire was developed to identify the needs of general education teachers. Respondents were asked to rate 27 statements that characterize their digital competence in organizing RL. Each statement had to be assessed in 2 aspects: existence of the mentioned skill (to what extent the skill is present, where 1 - the skill does not exist; 2 - poorly developed; 3 - average development; 4 - the skill at a high level) and necessity (how often the skill is needed to provide RL, where 1 - definitely not needed, 2 - rather no than yes, 3 - rather yes than no, 4 - definitely needed). The statements were grouped and formed the following criteria: Information Processing Skills, Communication, Curriculum Development, Security and Problem-Solving Skills. The questionnaire also included open-ended questions on recommendations at the level of national policy, school management, each class and teachers.

The survey was conducted online from August 25 to September 15, 2020; respondents answered questions anonymously. Using Raosoft calculation, it was determined that the set of respondents exceeds the minimum recommended size. In turn, the Cronbach's alpha coefficient $(\alpha=.955)$ indicates good internal coherence of the questionnaire and stability of measurements over time.

The teachers (559) from all regions of Latvia participated in the survey: Riga - $17 \%$, Kurzeme $-11.4 \%$, Vidzeme $-32.2 \%$, Zemgale $-6.3 \%$, Latgale $-30.1 \%$. Respondents are of different ages: $3.8 \%$ of respondents under 25 years of age, $13.8 \%$ of respondents between 26 and 35 years of age, $21.8 \%$ of respondents from 36 to 45 years of age, $36 \%$ of respondents from 46 to 55 years of age, but $24.6 \%$ of respondents are older than 55 years. $14.7 \%$ of respondents work in pre-school education level, $3.5 \%$ of respondents work in primary education stage I (Forms 1-6), $24.2 \%$ of respondents work in primary education stage II (Forms 7-9) and $26.7 \%$ of respondents work in secondary school. $64.8 \%$ of respondents have their main job in schools located in regional cities, $18.2 \%$ of respondents work in rural schools, the rest - in Riga.

As the online survey occurred in a short period of time, which coincided with the beginning of the school year and the introduction of the competency approach in general education, we assume that the most active teachers and those who are "in good relations" with the Internet took part in the survey. Therefore, there is a possibility that the results of the survey of all Latvian teachers could show lower results. Research highlights trends; in addition to online surveying, it is necessary to use other data acquisition tools for a more detailed understanding of the situation.

\section{Results and Discussion}

The analysis of the results compared the aspects of digital competence from the perspective of existence and necessity. Figure 1 shows that in terms of Information Processing Skills, respondents believe that their skills are at a higher level than necessary for the implementation of RL.

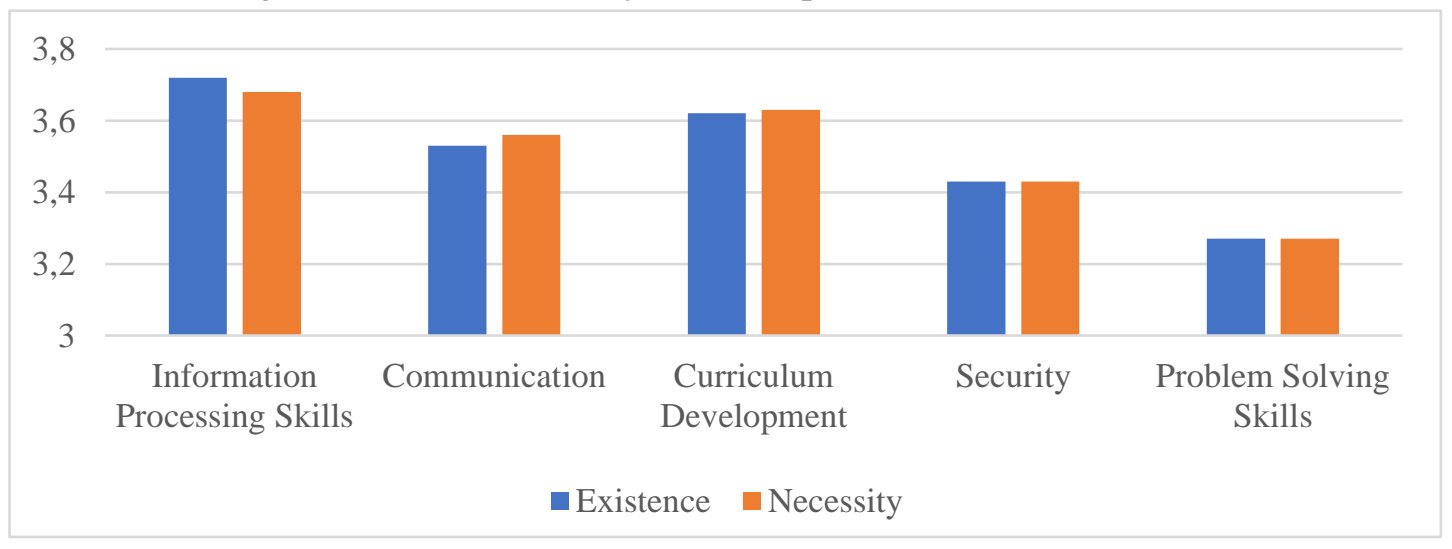

Figure 1. Comparison of existence and necessity of digital competence.

However, in terms of Security and Problem-Solving Skills, respondents consider that the existing competence meets the required level, although it must be acknowledged that respondents misunderstand 
the importance of security and problem-solving issues, because a detailed analysis of the survey's results shows that the self-assessment of several safety-related skills is the lowest (the average assessment is in the range from Rather yes than no to Rather no than yes). Responding to the open-ended questions, respondents express the opinion that the support of a qualified IT specialist is important in these questions. In terms of Communication and Curriculum Development, respondents believe that more skills are needed than they currently have.

The results showed statistically significant differences depending on the age of respondents, region, location of the educational institution (Riga, other city, countryside) and the level of education at which respondents work (Table 1).

Table 1

Statistically significant differences in the assessments of digital competence criteria

\begin{tabular}{|c|c|c|c|c|c|c|c|c|}
\hline \multirow{3}{*}{ Criterion } & \multicolumn{8}{|c|}{ Statistically significant differences (p) depending on } \\
\hline & \multicolumn{2}{|c|}{$\begin{array}{c}\text { age of } \\
\text { respondents }\end{array}$} & \multicolumn{2}{|c|}{ region } & \multicolumn{2}{|c|}{ location } & \multicolumn{2}{|c|}{$\begin{array}{l}\text { level of education } \\
\text { at which } \\
\text { respondents work }\end{array}$} \\
\hline & $\mathrm{E}$ & $\mathrm{N}$ & $\mathrm{E}$ & $\mathrm{N}$ & $\mathrm{E}$ & $\mathrm{N}$ & $\mathrm{E}$ & $\mathrm{N}$ \\
\hline Information Processing Skills & 0.000 & 0.000 & - & - & - & - & - & - \\
\hline Communication & 0.000 & 0.000 & - & - & - & - & - & - \\
\hline Curriculum Development & 0.000 & 0.000 & 0.005 & - & 0.004 & - & 0.004 & - \\
\hline Security & 0.000 & 0.000 & 0.034 & - & 0.022 & - & 0.003 & - \\
\hline Problem-Solving Skills & 0.000 & 0.000 & - & - & - & - & - & - \\
\hline
\end{tabular}

$N=559$

E-assessment of the existing competence

$N$ - assessment of the necessary competence

Depending on the age of respondents, statistically significant differences $(p=.000)$ were found in the evaluations of all criteria: in all cases, the younger respondents have a higher self-assessment, and the self-assessment decreases with age.

Depending on the location of an educational institution, statistically significant differences $(\mathrm{p}=.027)$ were found in the assessment of the criterion Communication: the highest self-assessment was received from employees of educational institutions in Riga (Mean 3.72), Kurzeme region (Mean 3.58) and Kurzeme cities (Mean 3.60), but the lowest - from employees of educational institutions in Latgale cities (Mean 3.44) and Latgale region (Mean 3.42).

Statistically significant differences were found depending on the region where a school is located:

- in the assessment of the criterion Communication $(\mathrm{p}=.005)$ the highest assessment was received from employees of educational institutions in Kurzeme region (Mean 3.80) and Riga (Mean 3.81), but the lowest - in Zemgale (Mean 3.66) and Latgale (Mean 3.69);

- in the assessment of the criterion Curriculum Development $(\mathrm{p}=.334)$ the highest assessment was received from educational institutions' workers in Riga (Mean 3.76) and Kurzeme region (Mean 3.64), but the lowest - in Latgale (Mean 3.54) and Vidzeme (Mean 3.61).

Depending on the location of an educational institution, statistically significant differences were found:

- in the assessment of the criterion Communication ( $\mathrm{p}=.004)$ the highest assessment was received from employees of Riga educational institutions (Mean 3.72), followed by employees of rural educational institutions (Mean 3.52) and employees of educational institutions of regional cities (Mean 3.49);

- in the assessment of the criterion Curriculum Development $(\mathrm{p}=.222)$ the highest assessment was received from employees of Riga educational institutions (Mean 3.76), followed by employees of rural educational institutions (Mean 3.63) and employees of educational institutions of regional cities (Mean 3.59).

As the level of education at which respondents work is an important factor in research, the self-assessments of various aspects of digital competence depending on the level of education were 
examined in more detail (Figure 2). As a result, it can be concluded that teachers working at a higher level of education have a higher self-assessment of digital competence than teachers working with learners at a lower level of education daily.

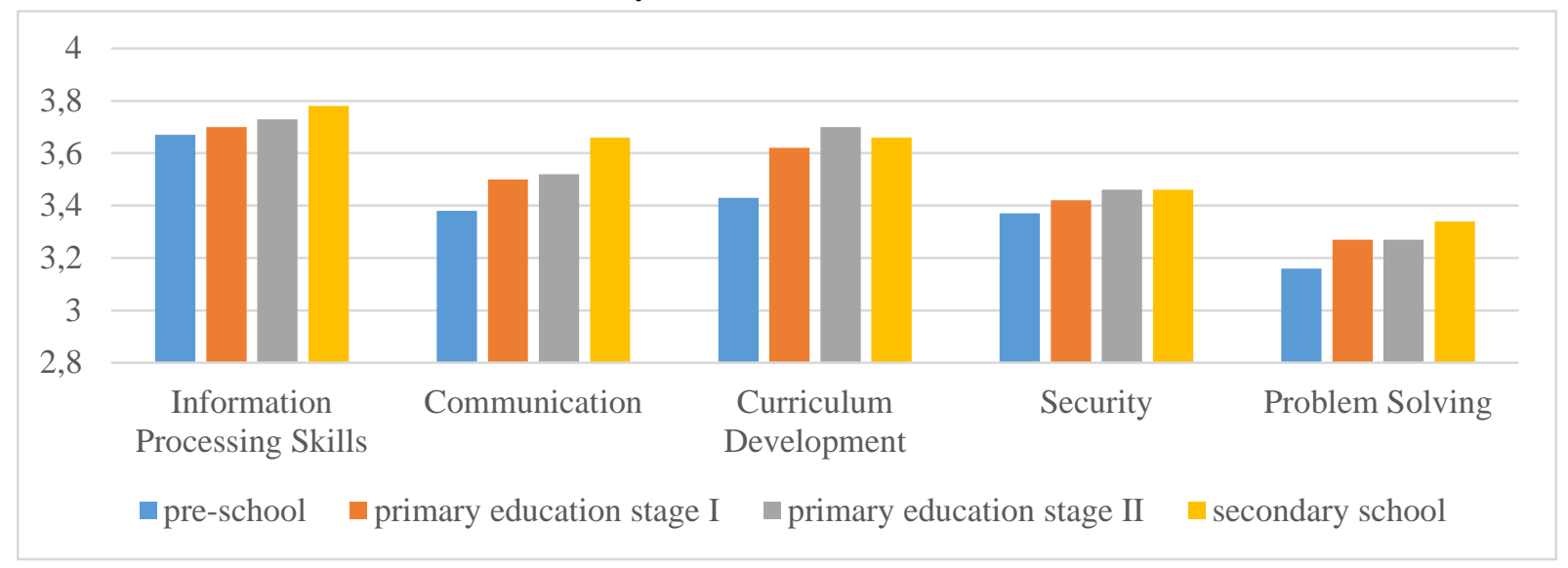

Figure 2. Self-assessment of digital competence aspects depending on the level of education in which respondents work.

Depending on the level of education at which respondents work, statistically significant differences were found in the assessment of the criteria Communication ( $\mathrm{p}=.004)$ and Curriculum Development $(\mathrm{p}=.018)$ : there is a tendency for the assessment to increase if a respondent works at a higher level of education. It should be recognized that the low level of digital competence of pre-school teachers has also been found in other researches (Creer, 2018; Romero-Tena et al., 2020), which indicate that relatively little use of ICT in pre-school education is explained not so much by the lack of technology, but by the insufficient digital competence of teachers to use ICT in professional career, as well as by insufficient methodological competence to integrate ICT in the process of teaching and learning.

Regardless of the age of learners with whom a teacher works, the question is important - how to organize teachers' digital competence development courses to make the remote learning process more successful, as $57.8 \%$ of respondents indicated in the survey that RL was of lower quality. How to change it? In the open-ended questions, respondents see opportunities at several levels:

- at the individual level, understood as a change of personal thinking and attitude, openness to cooperation, development of various skills (digital, time management, self-organization, communication and mutual trust), responsibility and self-reflection;

- at the level of the educational institution, when a clear operational strategy is developed, the digital tools to be used are defined, providing security and support measures, precise criteria for learning the content in RL are developed, communication and cooperation is ensured and further education is supported;

- at the municipal level, support is provided in the development and implementation of strategies, plans and internal regulatory documents, in the availability of highly qualified IT, social and psychological support, in the development of professional competence in accordance with specific needs in places;

- at the national level, a common platform for open access digital and interactive learning resources is set up, guidelines are being developed to define the mandate and responsibilities of the parties involved and various types of support (financial, social, psychological, methodological, educational) are provided.

Teachers emphasized the individual level, where the attitude towards remote learning, which became an everyday part of education due to the Covid-19 pandemic, is important. Attitude is a significant factor for the quality use of technology in the educational process, as it indicates the acceptance of technology and the intention to use it meaningfully for the implementation of a quality teaching process (Blume, 2020; Seufert, Guggemos, Sailer, 2021; Scherer, Teo, 2019).

The results of research show that the aspect of teachers' professional development is included at all levels, where the improvement of digital competence comes to the fore. Many respondents emphasize 
that pre-Covid-19 digital competence development courses have often been inconsistent with the situation teachers encountered during RL. Teachers' vision of the aspects of course organization is shown in Figure 3.

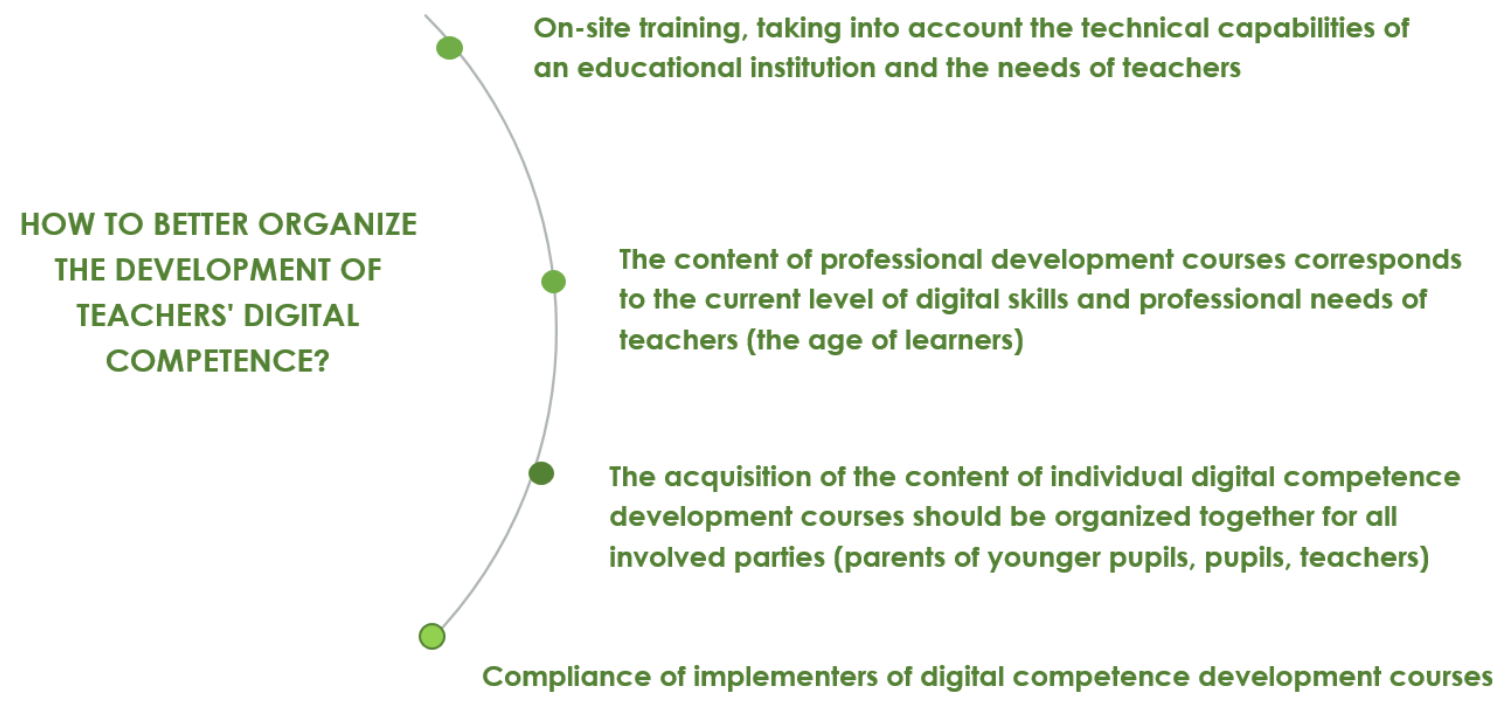

Figure 3. Development of digital competence according to the needs of teachers.

The first two proposals of teachers for successful course organization resonate with findings in the literature (Darling-Hammond, Hyler, Gardner, 2017; Hwang, Hong, Hao, 2018; Kong, Lai, Sun, 2020; Sentence, Csizmadia, 2017), when emphasizing several factors that increase the quality of teachers' development courses: 1) development is focused on practical classes and occurs over a longer period of time, when there are breaks to apply the acquired skills in practice. Campaigning or individual workshops do not produce the desired results; 2) teachers' further education is linked to the school context, so it is important to organize courses in groups, whose participants are in a similar situation on a daily basis and can discuss common problems they face in practice, seek solutions together and support each other in teaching and learning; 3 ) it is not enough to acquire specific technologies; the development of digital competence should be related to the acquisition of the field's content and didactics.

In relation to the compliance of providers of digital competence development courses, it is important to what extent the course organizers and managers understand the needs of teachers for the successful implementation of RL. If teachers feel understood, they will better accept the new reality and support and more successfully integrate the knowledge gained in the courses into their daily work (Sokal, Babb, Trudel, 2020).

The traditional triangle of interaction between learner - educator - learning content (regardless of the level of education) has not been abolished by anyone; therefore, it is important to place an emphasis not only on the aspect of acquiring technical digital skills, but also on how to organize the learning process in a more qualitative way (with more appropriate methods) according to the age of learners. Professional development courses need to develop not just digital competence, but pedagogical digital competence that refers to the use of pedagogical digital technologies to achieve goals related to the development of pupils' knowledge and understanding (List, Brante, Klee, 2020; Chien, Wu, 2020), when 3 aspects are important: 1) knowledge related to the various available technologies, their characteristics and interest in them; 2) the main theories and concepts of the specific field of study (for example, natural sciences, mathematics, language), the nature of knowledge and the means of research in the field; 3 ) knowledge of learning theories, i.e. learning processes and readiness to support and manage the learning situation and learning process. This means changing the requirements for course implementers: they need not only technological knowledge, but also an understanding of RL didactics and the peculiarities of pupils' age. Researches on the development of teachers' digital competence (Dillenbourg, 2013; Seufert, Guggemos, Sonderegger, 2020; Seufert, Guggemos, Sailer, 2021) show that the use of technology in education does not mean reducing the number of teachers but expanding their activities, and there is a risk that today's investment in certain digital skills will become obsolete in a few years' time. Therefore, continuous research is needed on the relevance and effectiveness of the use of different remote learning strategies. 
Course implementers must be flexible and keep pace with the latest research to offer teachers to improve their competence in the use of technology to implement a meaningful learning process. Professional development at work could be implemented by mentors - qualified practicing teachers with a positive experience in remote learning and a positive attitude towards technology. The experience of mentors educating and supporting their colleagues has been recognized in research (Seufert, Guggemos, Sailer, 2021; Tseng, Kuo, 2014; Yurtseven Avci, O'Dwyer, Lawson, 2020). Financial and organizational support is needed for its faster implementation in Latvia's educational institutions.

\title{
Conclusions
}

For successful implementation of RL, Latvia's teachers need to improve their pedagogical digital competence. Course implementers should rely on the TPACK model, where technological knowledge, pedagogical knowledge and knowledge of content are acquired in synergy.

Teachers' professional competence development courses should be practice-oriented, as close as possible to the technical possibilities of their educational institutions, as well as considering the current needs of teachers, the field of subjects taught and the level of education at which they work.

\section{Acknowledgement}
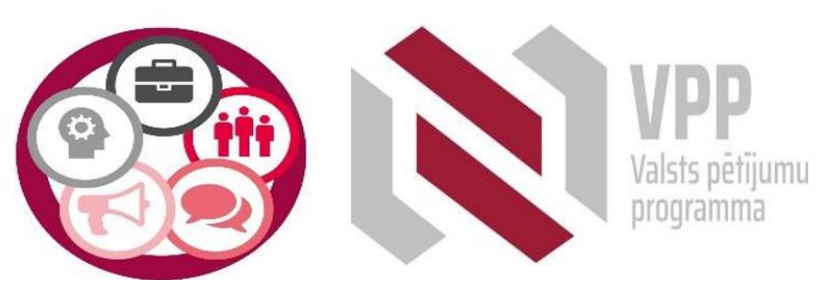

\begin{abstract}
This article was supported by the State Research programme project "Life with COVID-19: Evaluation of overcoming the coronavirus crisis in Latvia and recommendations for societal resilience in the future" (CoLife) Nr. VPP-COVID-2020/10013
\end{abstract}

\section{Bibliography}

1. Blume C. (2020). German Teachers' Digital Habitus and Their Pandemic Pedagogy. Postdigital Science and Education, 2, 879-905. doi: 10.1007/s42438-020-00174-9

2. Cabero-Almenara J., Gutiérrez-Castillo J.J., Palacios-Rodríguez A., Barroso-Osuna J. (2020). Development of the Teacher Digital Competence Validation of DigCompEdu Check-in Questionnaire in the University Context of Andalusia (Spain). Sustainability, 12, 6094. doi: $10.3390 /$ su 12156094

3. Chien S-P., Wu H-K. (2020). Examining influences of science teachers' practices and beliefs about technology-based assessment on students' performances: A hierarchical linear modeling approach. Computers \& Education, Volume 157, 103986. doi: 10.1016/j.compedu.2020.103986

4. Crawford J., Butler-Henderson K., Rudolph J., Malkawi B., Glowatz M., Burton R., Magni P.A., Lam S. (2020). COVID-19: 20 countries' higher education intra-period digital pedagogy responses Journal of Applied Teaching and Learning (JALT), 3(1). doi: 10.37074/jalt.2020.3.1.7

5. Creer A. (2018). Introducing Everyday 'Digital Literacy Practices' into the Classroom: An Analysis of Multi-layered Media, Modes and their Affordances. Journal of New Approaches in Educational Research, 7(2), 131-139. doi: 10.7821/naer.2018.7.265

6. Darling-Hammond L., Hyler M.E., Gardner M. (2017). Effective teacher professional development. Palo Alto, CA: Learning Policy Institute. Retrieved from https://static1.squarespace.com/static/56b90cb101dbae64ff707585/t/5ade348e70a6ad624d41733 9/1524511888739/NO_LIF 1.PDF

7. Dillenbourg P. (2013). Design for classroom orchestration. Computers \& Education, 69, 485-492. doi: 10.1016/j.compedu.2013.04.013

8. From J. (2017). Pedagogical Digital Competence-Between Values, Knowledge and Skills. Higher Education Studies, 7(2), 43-50. doi: 10.5539/hes.v7n2p43

9. Hew K.F., Lan M., Tang Y., Jia C., Lo C.K. (2019). Where is the "theory" within the field of educational technology research? British Journal of Educational Technology, 50(3), 956-971. doi: 10.1111/bjet.12770 
10. Hwang M.-Y., Hong J.-C., Hao Y.-W. (2018). The value of CK, PK, and PCK in professional development programs predicted by the progressive beliefs of elementary school teachers. European Journal of Teacher Education, 41(4), 448-462. doi: 10.1080/02619768.2018.1471463

11. Kong S-C., Lai M., Sun, D. (2020). Teacher development in computational thinking: Design and learning outcomes of programming concepts, practices and pedagogy. Computers \& Education, 151, 103872. doi: 10.1016/j.compedu.2020.103872

12. List A., Brante E.W., Klee H.L. (2020). A framework of pre-service teachers' conceptions about digital literacy: Comparing the United States and Sweden. Computers \& Education, 148, 103788. doi: 10.1016/j.compedu.2019.103788

13. Mishra P., Koehler M.J. (2006). Technological Pedagogical Content Knowledge: A Framework for Teacher Knowledge. Teachers College Record, 108(6), 1017-1054. Retrieved from http://one2oneheights.pbworks.com/f/MISHRA_PUNYA.pdf

14. Romero-Tena R., Barragán-Sánchez R., Llorente-Cejudo C., Palacios-Rodríguez A. (2020). The Challenge of Initial Training for Early Childhood Teachers. A Cross Sectional Study of Their Digital Competences. Sustainability, 12(11). doi: 10.3390/su12114782

15. Scherer R., Teo T. (2019). Unpacking teachers' intentions to integrate technology: A metaanalysis. Educational Research Review, 27, 90-109. doi: 10.1016/j.edurev.2019.03.001

16. Sentence S., Csizmadia A. (2017). Computing in the curriculum: Challenges and strategies from a teacher's perspective. Education and Information Technologies, 22(2), 469-495. doi: 10.1007/s10639-016-9482-0

17. Seufert S., Guggemos J., Sailer M. (2021). Technology-related knowledge, skills, and attitudes of pre- and in-service teachers: The current situation and emerging trends. Computers in Human Behavior, 115, 106552. doi: 10.1016/j.chb.2020.106552

18. Seufert S., Guggemos J., Sonderegger S. (2020). Digitale Transformation der Hochschullehre: Augmentationsstrategien für den Einsatz von Data Analytics und Künstlicher Intelligenz [Digital transformation of university teaching: Augmentation strategies for the use of data analytics and artificial intelligence]. Forschungsperspektiven auf Digitalisierung in Hochschulen, 15(1), 81-101. doi: 10.3217/zfhe-15-01/05 (in German)

19. Sokal L., Babb J., Trudel L.E. (2020). How to prevent teacher burnout during the coronavirus pandemic. Retrieved from https://theconversation.com/how-to-prevent-teacher-burnout-duringthe-coronavirus-pandemic-139353

20. Tseng F.C., Kuo F.Y. (2014). A study of social participation and knowledge sharing in the teachers' online professional community of practice. Computers \& Education, 72, 37-47. doi: 10.1016/j.compedu.2013.10.005

21. Yurtseven Avci Z., O'Dwyer L.M., Lawson J. (2020). Designing effective professional development for technology integration in schools. Journal of Computer Assisted Learning, 36(2), 160-177. doi: 10.1111/jcal.12394 